\title{
Pengaruh Perceived Organizational Support terhadap Individual Readiness for Change yang Dimediasi oleh Psychological Capital
}

\author{
M. Ahyar Putra ${ }^{1 *}$, Thatok Asmony ${ }^{2)}$, Siti Nurmayanti ${ }^{3)}$ \\ $\left.1^{*}, 2,3\right)$ Magister Manajemen, Fakultas Ekonomi dan Bisnis, Universitas Mataram \\ Jalan Pendidikan No.37, Mataram, Nusa Tenggara Barat, Indonesia. 83125 \\ E-mail: ahyar13.stiebima@gmail.com $\left.{ }^{1 *}\right)$
}

\begin{abstract}
ABSTRAK
Tujuh puluh persen organisasi gagal menerapkan perubahan di mana salah satu alasan utamanya adalah kurangnya kesiapan individu untuk berubah. Kesiapan individu untuk berubah adalah sejauh mana karyawan siap secara mental, psikologis atau fisik, siap untuk berpartisipasi dalam kegiatan pengembangan organisasi. Penelitian ini bertujuan untuk menguji peran persepsi dukungan organisasi terhadap kesiapan individu untuk berubah, dengan modal psikologis sebagai mediator. Data diperoleh dengan metode sensus menggunakan kuesioner dengan skala likert 1-5 pada 129 karyawan Universitas Bumigora. Pengujian hipotesis menggunakan analisis jalur dengan program SmartPLS 3.2.8. Hasil penelitian menunjukkan bahwa persepsi dukungan organisasi berpengaruh positif dan signifikan terhadap kesiapan individu untuk berubah, persepsi dukungan organisasi berpengaruh positif dan signifikan terhadap modal psikologis, namun modal psikologis tidak berpengaruh signifikan terhadap kesiapan individu untuk berubah dan tidak terbukti memediasi hubungan antara persepsi dukungan organisasi dan kesiapan individu untuk berubah.
\end{abstract}

Kata Kunci: Kesiapan Individu untuk Berubah; Persepsi Dukungan Organisasi; Modal Psikologis

\section{ABSTRACT}

Seventy percent of organizations failed to implement change where one of the main reasons was a lack of individual readiness to change. Individual readiness to change is the extent to which employees are ready mentally, psychologically or physically, are ready to participate in organizational development activities. This study aims to examine the role of perceived organizational support on individual readiness to change, with psychological capital as a mediator. Data obtained by the census method using a questionnaire with a Likert scale of 1-5 on 129 employees of the University of Bumigora. Hypothesis testing using path analysis with the SmartPLS 3.2.8 program. The results showed that perceptions of organizational support had a positive and significant effect on individual readiness to change, perceived organizational support had a positive and significant effect on psychological capital, but psychological capital was found to have no significant effect on individual readiness to change and was not proven to mediate the relationship between perceived organizational support and individual readiness for change.

Keywords: Individual Readiness to Change; Perceived Organizational Support; Psychological Capital,

\section{PENDAHULUAN}

Perubahan merupakan aspek penting untuk menciptakan manajemen yang efektif dan efisien, yang didorong oleh beberapa hal seperti laju perkembangan global yang pesat, risiko 
bisnis, kesempatan yang menggairahkan, inovasi dan sistem kepemimpinan yang baru (Madsen, S. R. et al., 2013). Armenakis, et al (1999) menggambarkan tiga tahap dalam perubahan organisasi yaitu kesiapan, adopsi, dan institusionalisasi. 70\% organisasi telah gagal dalam implementasi perubahan (Miller \& Monge, 1985). Bruch, et al (2005) mengatakan hanya $50 \%$ organisasi yang telah berhasil dalam intervensi perubahan skala besar. Persentase keberhasilan organisasi dalam menerapkan perubahan tersebut jelas bukanlah suatu yang membanggakan sehingga penting untuk dengan cermat melihat faktor yang dapat menjadi penghambat dan pendorong dalam keberhasilan perubahan.

Holt, et al (2010) mengatakan bahwa faktor kesiapan berubah dapat dilihat dari sudut pandang organisasional dan individual, baik secara psikologis maupun struktural. Individual rediness for change kemudian menjadi sangat penting sebab mereka adalah unsur yang akan secara langsung terdampak dari adanya perubahan organisasi. Sehingga sangat mungkin siap atau tidak siapnya individu dalam organisasi dapat menjadi penentu berhasil atau tidaknya suatu perubahan. Shah et al, (2017) dalam meta analisis yang dilakukannya menemukan bahwa secara organisasional individual readiness for change dapat dipengaruhi oleh perceived organizational support, sementara dari faktor individual dapat didorong oleh self efficacy dan personal resiliency yang merupakan indicator dari psychological capital (Luthans et al., 2007).

Hanpachern, et al (1998) mengatakan individual readiness for change merupakan sejauh mana karyawan siap secara mental, psikologis atau fisik, sedia untuk berpartisipasi dalam aktivitas pengembangan organisasi. Serta terdiri dari komponen afektif, kognitif dan intensional. Komponen afektif merujuk pada perasaan seseorang terhadap perubahan yang ada dan melibatkan aspek emosional dalam menghadapi perubahan, komponen kognitif melibatkan apa yang orang pikirkan tentang perubahan, sedangkan komponen intensional merujuk pada perilaku seseorang terhadap perubahan dan melibatkan komitmen dalam melaksanakan perubahan (Bouckenooghe \& Devos, 2007). Perceived organizational support mengacu pada persepsi karyawan mengenai sejauh mana organisasi menghargai kontribusi dan peduli terhadap kesejahteraan mereka (Eisenberger et al., 1986). Juga keyakinan, bahwa organisasi akan membantu dalam menyelesaikan pekerjaan dengan efektif atau dalam menghadapi situasi menekan, serta penilaian terhadap kebijakan dan prosedur organisasi, yang terbentuk berdasarkan pengalaman terhadap kebijakan dan prosedur organisasi, penerimaan sumber daya, interaksi dengan agen organisasinya (misalnya supervisor), dan persepsi kepedulian organisasi terhadap kesejahteraan karyawan (Rhoades \& Eisenberger, 2002). Luthans, et al (2007) mengatakan bahwa Psychological Capital adalah keadaan 
perkembangan psikologi positif individu yang ditandai dengan adanya kepercayaan diri (selfefficacy) untuk dapat menyelesaikan tugas yang menantang, memiliki atribusi positif (optimism) tentang keberhasilan di masa sekarang dan masa depan, tetap mengejar tujuan dan mengatur ulang cara mencapai tujuan jika diperlukan (hope) agar berhasil, dan dapat bertahan bahkan menjadi lebih baik dari sebelumnya ketika mengalami kesulitan dan masalah (resiliency) untuk memperoleh kesuksesan.

Penelitian yang dilakukan oleh Gigliotti, et al (2019), Rochmi dan Hidayat (2019), Jabbarian dan Chegini (2017), serta Kirrane, et al (2017) secara konsisten menemukan bahwa perceived organizational support akan berdampak terhadap meningkatnya individual readiness for change. Ketika perceived organizational support karyawan tinggi, mereka percaya bahwa organisasi peduli terhadap mereka dan apa yang menjadi rencana organisasi kedepannya berkaitan dengan perubahan adalah demi kebaikan mereka dan mendukungnya jika perubahan itu rasional (Self et al., 2007). Selama terjadinya proses perubahan organisasi, karyawan terutama yang resisten terhadap perubahan mungkin akan mendapati energinya yang terkuras baik secara fisik maupun emosional, namun efek negative ini dapat ditekan dan dikurangi ketika perceived organizational support karyawan tinggi (Turgut et al., 2016). Pada penelitian yang sama, Jabbarian dan Chegini (2017), Kirrane, et al (2017), serta penelitian lainnya yang dilakukan oleh Munawaroh dan Meiyanto (2017), Ming-Chu dan Meng-Hsiu (2015) dan Avey, et al (2008) menemukan bahwa psychological capital berpengaruh dalam meningkatkan individual readiness for change. Komponen dari psychological capital membuat karyawan dapat mengatasi tantangan dari perubahan organisasi, dan dengan emosi positif tersebut maka sikap sinis terhadap perubahan organisasi akan diturunkan (Avey et al., 2008), serta mengurangi kecemasan, stress kerja, dan keinginan untuk meninggalkan organisasi ketika dalam situasi yang menekan seperti dalam perubahan organisasi (Avey et al., 2011).

Kendati beberapa penelitian terdahulu konsisten menemukan bahwa perceived organizational support berpengaruh signifikan terhadap individual readiness for change, namun dalam penelitian yang dilakukan oleh Al-Hussami, et al (2018) menemukan hasil yang tidak signifikan. Sehingga peneliti berasumsi bahwa psychological capital dalam penelitian ini juga dapat memediasi hubungan antara perceived organizational support dan individual readiness for change, sebab menurut Eisenberger, et al (2001) rasa dukungan karyawan dari supervisor atau dari pihak manajemen lebih bersifat persepsi subjektif (psikologis) daripada fakta yang dapat diverifikasi secara objektif. Beberapa penelitian sebelumnya juga mendukung asumsi ini seperti Kirrane, et al (2017) yang menemukan bahwa psychological 
capital memediasi hubungan antara perceived management support terhadap kesiapan berubah, serta Luthans, et al (2008) dimana psychological capital ditemukan memediasi hubungan antara iklim organisasi yang mendukung dan kinerja karyawan. Luthans, et al (2007) juga mengemukakan bahwa efikasi diri, optimisme, dan harapan dapat meningkat dan dipengaruhi oleh orang lain. Sementara iklim organisasi yang mendukung sangat berperan dalam meningkatkan ketahanan (resiliency) karyawan (Luthans et al., 2008).

Penelitian ini dilakukan pada Universitas Bumigora yang terbentuk pada akhir tahun 2018 dari penggabungan dua perguruan tinggi, yaitu STMIK (Sekolah Tinggi Manajemen Informasi dan Komputer) dan STIBA (Sekolah Tinggi Ilmu Bahasa Asing) Bumigora. Perubahan tersebut mendorong para karyawan untuk mampu beradaptasi dengan pola kerja dan struktur organisasi yang berbeda. Dibukanya beberapa program studi baru pasca penggabungan serta merta mendorong terjadinya peningkatan jumlah mahasiswa yang berdampak pada meningkatnya beban pelayanan yang harus diberikan oleh karyawan baik staf pengajar maupun non pengajar. Perubahan yang terjadi tersebut pada staf pengajar berdampak pada berubahnya jadwal mengajar mereka yang disesuaikan dengan jadwal baru berdasarkan peraturan Universitas serta jumlah jam mengajar dan jumlah mahasiswa yang kemudian bertambah dari sebelumnya. Pada staf akademik perubahan yang terjadi ini mengharuskan mereka berada dalam ruang lingkup kerja yang baru dengan rekan kerja yang berbeda pula di bawah Universitas Bumigora dari perguruan tinggi tempat mereka mengabdi sebelumnya yaitu STMIK dan STIBA Bumigora. Meski telah banyak penelitian dengan topic perubahan organisasi, namun belum peneliti temukan konteks perubahan yang berkaitan dengan penggabungan (merger) antara dua atau lebih organisasi. Bebenroth dan Bartnik (2019) yang mengacu pada teori identitas sosial, mengatakan bahwa dalam perubahan organisasi seperti merger dan akuisisi karyawan sering bereaksi negative. Sehingga penelitian ini diharapkan dapat memberi sumbangsih untuk penelitian-penelitian lain kedepannya.

Berdasarkan pembahasan tersebut di atas, kami membangun hipotesis:

1. Perceived organizational support berpengaruh positif dan signifikan terhadap individual readiness for change

2. Psychological capital berpengaruh positif dan signifikan terhadap individual readiness for change

3. Perceived organizational support berpengaruh positif dan signifikan terhadap psychological capital

4. Psychological capital memediasi hubungan antara perceived organizational support dan individual readiness for change 


\section{METODE PENELITIAN}

Jenis penelitian ini adalah penelitian asosiatif kausal dengan pendekatan kuantitatif. Penelitian ini digunakan untuk mengetahui pengaruh perceived organizational support dan psychological capital terhadap individual readiness for change. Sebanyak 189 orang responden dari Universitas Bumigora yang baru saja mengalami perubahan organisasi dari penggabungan STMIK dan STIBA Bumigora dikirimkan kusioner online dengan tingkat pengembalian kusioner sebesar 71\% (129 orang). Ukuran individual readiness for change didasarkan pada instrument yang dikembangkan oleh Bouckenooghe, et al (2009) yang terdiri 14 item pernyataan berdasarkan tiga dimensi yaitu Emotional, Cognitive, dan Intentional readiness for change. Sedangkan perceived organizational support terdiri dari 31 item pernyataan yang dikembangkan oleh Eisenberger, et al (1986) dan Burns (2016) dengan tiga dimensi yaitu Fairness of treatment, Supervisor support, dan Organizational rewards and job conditions. Sementara psychological capital diukur menggunakan 22 item pernyataan yang dikembangkan oleh Luthans, et al (2007) dengan empat dimensi yaitu Self efficacy, Optimism, Hope, dan Resiliency. Masing-masing instrument penelitian diukur dengan menggunakan skala likert 1-5 dari sangat tidak setuju sampai sangat setuju. Analisisis data dilakukan dengan menggunakan bantuan aplikasi SmartPLS. Nilai rata-rata dari masing-masing responden dapat dikelompokkan dalam 5 (lima) kelas interval. Panjang interval kelas dapat dihitung dengan rumus berikut:

$$
\text { Panjang kelas interval }=\frac{\text { skor tertinggi-skor terendah }}{\text { jumlah kelas }}=\frac{5-1}{5}=0,8
$$

\section{Tabel 1. Distribusi Interval Kelas Variabel Penelitian}

\begin{tabular}{cccc}
\hline Interval & IRFC & PsyCap & POS \\
\hline $4,21-5,00$ & Sangat Siap & Sangat Kuat & Sangat Mendukung \\
$3,41-4,20$ & Siap & Kuat & Mendukung \\
$2,61-3,40$ & Cukup Siap & Cukup Kuat & Cukup Mendukung \\
$1,81-2,60$ & Tidak Siap & Lemah & Tidak Mendukung \\
$1-1,80$ & Sangat Tidak Siap & Sangat Lemah & Sangat Tidak Mendukung \\
\hline \multicolumn{2}{l}{ Sumber: Data primer diolah, 2020 } & &
\end{tabular}

\section{HASIL DAN PEMBAHASAN}

Distribusi tanggapan responden menunjukkan bahwa karyawan pada Universitas Bumigora secara rata-rata mengaku dirinya siap untuk berubah dimana didapati mean sebesar 4,13. 71 orang karyawan mengaku "sangat siap" dan 48 orang mengaku "siap", namun 
ditemukan 1 orang respoden yang berada pada kategori "tidak siap" serta sembilan orang responden pada kategori "cukup siap". Perceived organizational support ditemukan memiliki mean sebesar 3,94 yang berarti bahwa secara rata-rata dari 129 responden yang menjadi subyek penelitian memiliki persepsi bahwa organisasi "mendukung" mereka dengan adanya keadilan struktural dan aspek sosial, dukungan dari penyelia dengan adanya sikap peduli pada karyawan, serta malalui alokasi rewards dan kondisi kerja yang mendukung. Akan tetapi masih terdapat setidaknya 3 orang responden yang merasa bahwa organisasi "tidak mendukung", serta 15 orang yang merasa bahwa organisasi hanya "cukup mendukung". Secara rata-rata nilai psychological capital responden adalah sebesar 4,07 atau berada dalam kategori "kuat", hal tersebut menunjukkan bahwa karyawan pada Universitas Bumigora telah memiliki efikasi diri, optimisme, ketahanan, dan harapan yang positif terhadap keberadaannya dalam organisasi. Bahkan untuk dimensi optimisme ditemukan berada lama kategori "sangat kuat" (mean 4,21). Namun masih terdapat 8 orang responden yang memiliki psychological capital hanya dalam kategori "cukup".

Hasil dari tabulasi data secara garis besar menunjukkan bahwa tidak terdapat perbedaan persepsi dari responden terhadap variabel yang diteliiti berdasarkan jenis kelamin, asal perguruan tinggi sebelumnya, dan status kepegwaian. Akan tetapi ada sebuah temuan yang menarik bahwa karyawan yang berusia di atas 50 tahun mengaku "sangat siap" untuk berubah (mean 4,24), memiliki psychological capital yang "sangat kuat" (mean 4,21), dan merasa bahwa organisasi telah "sangat mendukung" mereka (mean 4,24). Kami menduga bahwa hal tersebut disebabkan karena karyawan yang berusia di atas 50 tahun telah cukup memiliki kematangan dalam berpikir dan dalam karirnya sebab mereka merupakan orangorang yang telah cukup lama berada dalam dunia kerja, sementara pada karyawan dengan rentang usia dibawahnya masih dalam tahap mencari apa yang bagus dan tidak untuk dirinya.

Uji prasyarat analisis dilakukan, dengan evaluasi terhadap nilai loading factor, average variance extracted (AVE), serta composite reliability dimana item-item indikator yang tidak memenuhi syarat kemudian dieliminasi dari model penelitian. Menurut Ghozali dan Latan (2015) variabel laten harus memiliki nilai AVE yang lebih besar dari 0,5 dan composite reliability yang lebih besar dari 0,7. Pada tabel 2, ditemukan setelah melewati prasyarat analisis ditemukan model penelitian telah memenuhi standar yang ditentukan.

Tabel 2. Evaluasi Model

\begin{tabular}{llc}
\hline \multicolumn{1}{c}{ Variabel } & AVE & Composite Reliability \\
\hline Individual Readiness For Change & 0.504 & 0.929 \\
Perceived Organizational Support & 0.500 & 0.955 \\
Psychological Capital & 0.502 & 0.909 \\
\hline
\end{tabular}




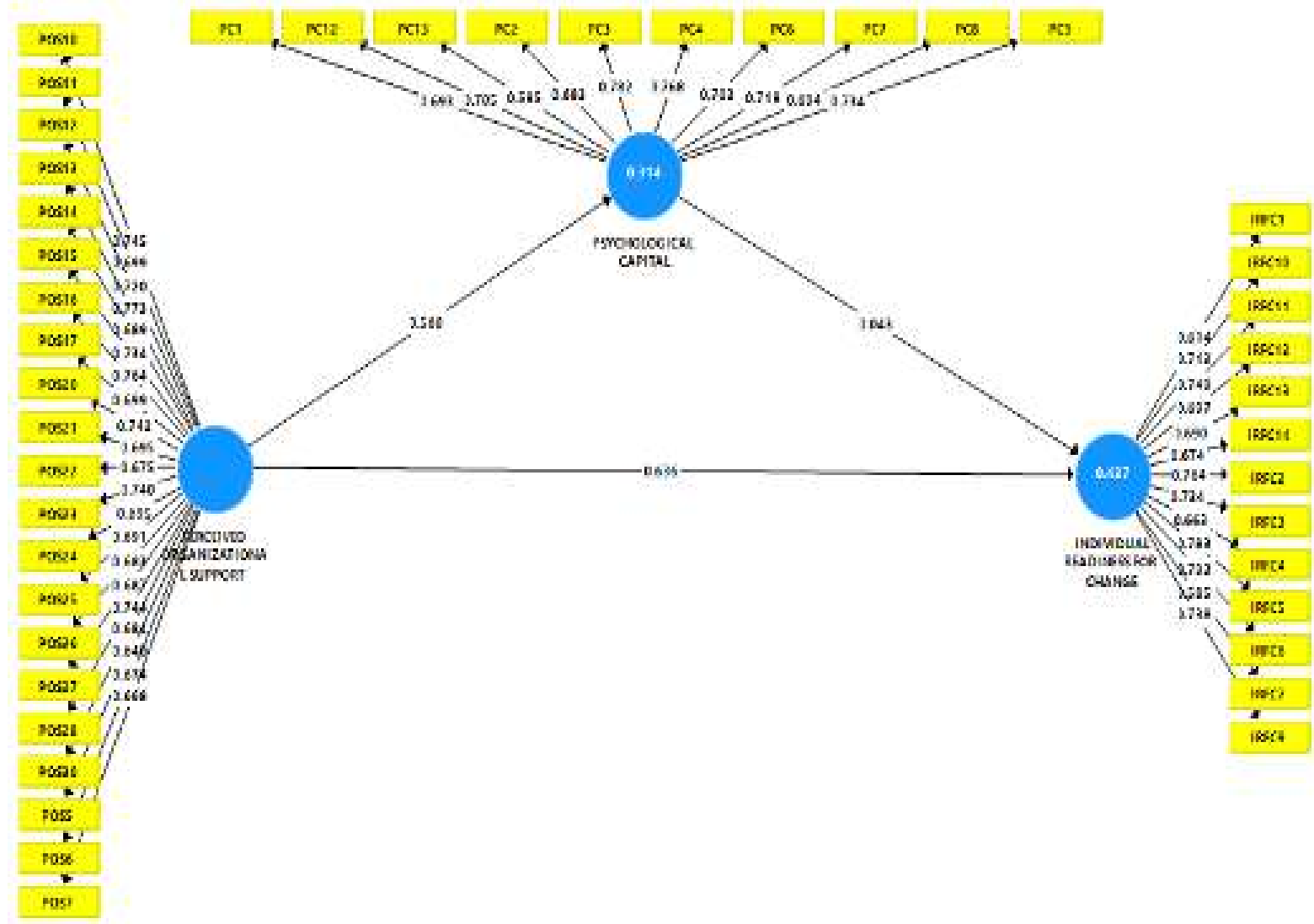

\section{Gambar 1. Model Setelah Modifikasi}

Sumber: Data Perimer Diolah, 2020.

Koefisien determinasi $\left(\mathrm{R}^{2}\right)$ menunjukkan nilai 0,437 untuk variabel individual readiness for change yang berarti IRFC dipengaruhi sebesar 43,7\% oleh POS dan PsyCap. Sementara $\mathrm{R}^{2}$ Psychological capital sebesar 0,314 atau sebesar 31,4\% dipengaruhi oleh perceived organizational support. Hasil uji $\mathrm{Q}^{2}$ dengan menggunakan metode blindfolding menunjukkan nilai 0,195 untuk variabel IRFC dan 0,139 untuk PsyCap dimana menuruh Hair, et al (2017) jika nilai $\mathrm{Q}^{2}$ lebih besar dari 0 menunjukkan model penelitian telah memiliki kemampuan prediksi yang baik. Ghozali dan Latan (2015) mengatakan hipotesis diterima apabila nilai $t$-statistics berada di atas t-tabel atau nilai p-value berada di bawah level of significant yang dalam penelitian ini adalah 5\% atau 0,05. Nilai t-tabel dengan jumlah responden 129 didapatkan adalah 1,98. Tabel 3 memberikan gambaran hasil pengujiannya.

Tabel 3. Koefisien Jalur pada Pengujian Struktural

\begin{tabular}{lcccc}
\hline $\begin{array}{c}\text { Hubungan Antar } \\
\text { Variabel }\end{array}$ & $\begin{array}{c}\text { Nilai } \\
\text { Koefisien }\end{array}$ & $\begin{array}{c}\text { T } \\
\text { Statistics }\end{array}$ & $\begin{array}{c}\text { P } \\
\text { Values }\end{array}$ & Keterangan \\
\hline POS -> IRFC & 0,636 & 8,022 & 0.000 & Positive and significant \\
PsyCap -> IRFC & 0,043 & 0,446 & 0.656 & Positive and not significant
\end{tabular}




\begin{tabular}{llllc} 
POS -> PsyCap & 0.560 & 7,818 & 0.000 & Positive and significant \\
POS -> PsyCAp -> IRFC & 0,024 & 0,419 & 0,675 & No mediation \\
\hline
\end{tabular}

Sumber : Data Perimer Diolah, 2020.

Analisis data menunjukkan hubungan yang positif dan signifikan antara perceived organizational support dan individual readiness for change. Jika perceived organizational support karyawan meningkat, maka kesiapan mereka untuk menghadapi perubahan organisasi juga akan mengalami peningkatan dan sebaliknya jika perceived organizational support kurang dirasakan oleh karyawan akan membuat karyawan menolak adanya perubahan. Eisenberger, el al (1986) menjelaskan bahwa POS akan meningkatkan harapan karyawan bahwa organisasi akan menghargai upaya yang lebih besar untuk mencapai tujuan organisasi sehingga hal tersebut akan berpengaruh terhadap kesiapan mereka untuk berubah dengan harapan ketika perubahan itu berhasil, karyawan akan mendapat sesuatu yang lebih baik lagi dari yang mereka terima pada saat sebelum proses perubahan. Ketika karyawan telah memiliki POS yang baik, mereka percaya bahwa organisasi peduli dan apa yang menjadi rencana organisasi kedepannya adalah demi kebaikan mereka (Self et al., 2007). Pikiranpikiran subjektif akan kesuksesan karir dimasa depan dengan adanya perubahan organisasi akan berpengaruh terhadap IRFC (Al-Hussami et al., 2018).

Dukungan yang diberikan oleh pimpinan secara praktis dan emosional kepada para karyawan menunjukkan adanya komitmen dari petinggi-petinggi organisasi terhadap proses perubahan dan kesediaan mereka untuk mendukung karyawan dalam menghadapi tantangan yang timbul dari perubahan. Menurut Northouse, dalam (Al-Hussami et al., 2018) hal tersebut dapat memfasilitasi IRFC secara positif. Dukungan organisasi yang diberikan dengan baik dan adil kepada karyawan melalui reward and job conditions pada saatnya akan menumbuhkan kenyamanan dan perasaan aman secara psikologis dalam diri individu karyawan ketika dihadapkan dalam situasi yang penuh ketidakpastian seperti selama perubahan organisasi (Neves \& Eisenberger, 2014). Temuan dalam penelitian ini sejalan beberapa penelitian lain di antaranya oleh (Gigliotti et al., 2019; Jabbarian \& Chegini, 2017; Kirrane et al., 2017; Ming-Chu \& Meng-Hsiu, 2015; Rochmi \& Hidayat, 2019) yang secara konsisten menemukan bahwa perceived organizational support akan berdampak terhadap individual readiness for change.

Psychological capital ditemukan tidak berpengaruh signifikan terhadap individual readiness for change ( $p 0,656>0,05)$. Temuan ini bertolak belakang dengan penelitian yang dilakukan oleh (Avey et al., 2008; Jabbarian \& Chegini, 2017; Kirrane et al., 2017; Ming-Chu \& Meng-Hsiu, 2015; Munawaroh \& Meiyanto, 2017). Peneliti menduga bahwa hasil yang 
berbeda ini disebabkan karena kepercayaan diri, optimisme, harapan, dan ketahanan karyawan itu terkait dengan keadaan yang dialami dan dapat mereka terka saat ini (bukan berkaitan dengan keadaan yang tidak bisa mereka duga seperti perubahan organisasi) yang secara struktural seperti dikatakan Holt, et al (2010) mengharuskan mereka untuk siap dari segi pengetahuan, kompetensi, dan kemampuan yang berkaitan dengan perubahan (yaitu sejauh mana pengetahuan, kompetensi, dan kemampuan individu sesuai dengan pengetahuan, kompetensi, dan kemampuan yang dibutuhkan dalam perubahan).

Kirrane, et al (2017) mengatakan ketika organisasi berjalan lancar dan karyawan memiliki sumber daya yang baik dan terbiasa dengan peran mereka, kinerja pekerjaan mungkin positif secara universal dan efek dari tingkat psychological capital pribadi yang berbeda tidak akan dapat terlihat. Namun dalam kondisi pengujian yang tidak biasa, seperti yang terlibat dalam perubahan organisasi, perbedaan kemampuan beradaptasi individu dengan psychological capital yang tinggi dan rendah menjadi paling jelas. Luthans, et al (2007) juga mengatakan bahwa psychological capital adalah variabel keadaan yang dapat menguat atau melemah sepanjang waktu dan sesuai dengan konteks yang dihadapi oleh individu dalam organisasi. Pandangan tersebut juga dapat menjadi alasan, sebab penelitian dilakukan setelah lebih dari satu tahun pasca penggabungan antara STMIK dan STIBA Bumigora dimana situasi-situasi akibat dari perubahan cenderung telah kondusif dan telah dapat ditangani oleh para karyawan.

Perceived organizational support berpengaruh positif dan signifikan terhadap psychological capital, ketika karyawan merasa organisasi telah memberikan dukungan kepada mereka melalui keadilan struktural dan pengalokasian sumber daya yang baik, mendengar apa yang menjadi keluhan dan kebutuhan karyawan, mengalokasikan reward and job condition yang layak, memotivasi dan memahami tujuan karyawan dalam organisasi, hingga otonomi yang diberikan organisasi maka akan mengembangkan suatu persepsi secara umum bahwa organisasi mendukung mereka yang kemudian akan meningkatkan rasa percaya diri, optimisme, ketahanan, dan harapan karyawan yang merupakan unsur dari psychological capital dan sebaliknya ketika karyawan merasa bahwa organisasi belum cukup mendukung mereka, maka psychological capital karyawan akan menurun atau melemah.

Luthans, et al (2007) mengatakan bahwa self efficacy, optimism, dan hope dapat dipengaruhi oleh orang lain berupa penilaian yang positif terhadap diri individu, adanya keterlibatan, komunikasi yang baik antara bawahan dan atasan, dan pemberian otonomi sehingga individu mampu meningkatkan keyakinan terhadap kemampuannya serta selalu optimis dalam melaksanakan setiap tugas yang diberikan. System reward dan pengalokasian 
sumber daya yang baik berperan dalam meningkatkan harapan karyawan dalam usahanya untuk mencapai tujuan, individu yang sulit mendapatkan akses terhadap hal-hal yang diperlukannya dalam mencapai tujuan akan lebih cepat membuatnya bersikap apatis. Teori pertukaran sosial mengatakan bahwa ketika terjadi proses saling ketergantungan dan saling menguntungkan antara organisasi dan karyawan, akan mendorong tumbuhnya psychological capital seseorang sesuai dengan besar kecilnya keuntungan yang didapatkan dari hubungan tersebut (Emerson, 1976). Berbanding terbalik ketika orgnisasi melalui pimpinan menunjukkan perilaku yang kasar dan tidak mendukung terhadap bawahan (Avey, 2014). Dalam organisasi yang mendukung menurut Luthans, et al (2008) dapat meningkatkan resiliency dan memungkinkan individu untuk pulih atau bangkit dengan cepat ketika berada dalam situasi kemunduran seperti ketika karyawan merasa frustasi dengan kesalahan mereka sendiri, dalam iklim organisasi yang mendukung mereka cenderung cepat pulih karena tidak khawatir akan dihukum. Akhirnya, Temuan dalam penelitian ini mempertegas kembali hasil dari beberapa riset awal seperti yang dilakukan oleh (Hui et al., 2014; Ming-Chu \& MengHsiu, 2015; Sihag \& Sarikwal, 2015; Wu \& Nguyen, 2019) yang menemukan bahwa perceived organizational support berpengaruh signifikan terhadap individual readiness for change.

Dalam penelitian ini psychological capital tidak terbukti mampu memediasi hubungan antara POS dan IRFC. Hair, et al (2017) mengkategorikan temuan seperti ini sebagai directonly nonmediation yaitu ketika pengaruh langsung signifikan dan pengaruh tidak langsung tidak signifikan. Artinya, variabel perceived organizational support tanpa adanya psychological capital akan tetap mampu mempengaruhi individual readiness for change pada karyawan Universitas Bumigora. Temuan ini memberikan gambaran bahwa interpretasi atau penafsiran karyawan terhadap dukungan organisasi yang kemudian memengaruhi individual readiness for change tidak dilandaskan pada karakteristik individu (subjektif) namun lebih bersifat objektif. Luthans, et al (2008) juga mengatakan bahwa walaupun perceived organizational support sudah cukup tinggi, hal tersebut tidak kemudian selalu menghasilkan tingkat kesuksesan yang konsisten jika seseorang tidak memiliki bakat atau kapasitas individu untuk melaksanakan tugas, jadi peneliti berasumsi bahwa walaupun POS berpengaruh terhadap peningkatan PsyCap karyawan, tidak serta merta hal tersebut dapat secara bersamasama mendorong individual readiness for change, jika psychological capital yang tumbuh dari hubungan itu tidak terbentuk dari suatu pertimbangan akan bakat dan kapasitas mereka dalam menghadapi keadaan yang dibawa oleh perubahan organisasi. 
Hobfoll (2002) mengatakan bahwa individu akan mengumpulkan sumber daya yang dapat mereka terapkan atau yang mereka butuhkan untuk mengatasi tantangan dan ancaman. Mereka mungkin saja akan mengumpulkan sumber daya pribadi (seperti psychological capital) atau sumber daya yang berasal dari lingkungan sosial (seperti organizational support). Psychological capital yang tidak terbukti memediasi hubungan antara POS dan IRFC peneliti duga disebabkan karena adanya asumsi dari para karyawan bahwa situasisituasi yang menantang dari adanya perubahan organisasi sudah cukup dapat mereka hadapai dengan adanya dukungan organisasional yang baik. Temuan ini tidak sejalan dengan apa yang dikatakan oleh Eisenberger, et al (2001) bahwa cara dukungan manajemen yang dirasakan memengaruhi kesiapan untuk berubah cenderung bersifat psikologis daripada material semata. Penelitian ini bertolak belakang dengan hasil penelitian lain seperti oleh Kirrane, et al (2017) yang menemukan bahwa psychological capital memediasi hubungan antara perceived management support dan individual readiness for change, dan penelitian yang dilakukan oleh Luthans, et al (2008) dimana psychological capital ditemukan memediasi hubungan antara iklim organisasi yang mendukung dan kinerja karyawan.

\section{KESIMPULAN DAN SARAN}

Berdasarkan analisis koefisien jalur menunjukkan (1) Perceived organizational support berpengaruh positif dan signifikan terhadap individual readiness for change (2) Psychological capital berpengaruh positif tetapi tidak signifikan terhadap individual readiness for change (3) Perceived organizational support berpengaruh positif dan signifikan terhadap modal psikologis (4) Psychological capital tidak terbukti memediasi hubungan antara perceived organizational support dan individual readiness for change. Hasil penelitian ini menunjukkan bahwa individual readiness for change cenderung lebih ditentukan oleh faktor lingkungan organisasi dibanding dengan faktor-faktor individu yang melekat seperti psychological capital. Hal tersebut kemudian menjadi penting, bahwa dalam penentu keberhasilan suatu program perubahan akan sangat bergantung terhadap bagaimana organisasi memperlakukan individu dan kelompok individu dalam organisasi termasuk dalam menciptakan iklim yang mendukung.

Kami menyarankan bahwa organisasi harus mempertimbangkan bagaimana meningkatkan individual readiness for change. Ketika karyawan memiliki pemahaman yang jelas dan benar tentang tujuan dan isi perubahan, mereka akan membangun sikap positif terhadap penyampaian perubahan. Lebih lanjut, jika karyawan menganggap bahwa perubahan itu bermanfaat, mereka akan menurunkan rasa terkucilkan dan meningkatkan niat untuk 
berubah. Ini mendorong inovasi dan menciptakan lingkungan yang memiliki efek positif pada promosi perubahan organisasi. Diharapkan organisasi dapat menciptakan kesiapan untuk berubah secara bertingkat dengan menargetkan peningkatan perceived organizational support. Inisiatif perubahan oleh organisasi dari atas ke bawah akan memiliki efek terbatas jika tidak memperhatikan keadilan dalam pengalokasian sumber daya, dukungan manajemen, reward, dan kondisi kerja sebagai komponen dari POS. Tidak kuatnya hubungan antara psychological capital terhadap individual readiness for change sehingga organisasi dapat menyingkirkan kekhawatiran akan optimisme karyawan, harapan, kepercayaan diri, dan ketahanan terhadap dampaknya untuk kesiapan berubah, tetapi tetap perlu untuk memantaunya, melihat bahwa unsur dalam modal psikologis sangat berguna dalam berjalannya kegiatan organisasional yang lambat laun akan menjadi budaya yang dengan itu organisasi dapat menilai seberapa baik organisasi telah berjalan.

Penelitian ini tentu sangatlah terbatas pada beberapa hal sehingga masih perlu untuk ditinjau dan dikembangkan lagi untuk penelitian-penelitian selanjutnya dengan melihat pada sudut pandang lain sebab dalam penelitian ini variabel-variabel yang diajukan hanya berpengaruh kurang dari 50\% terhadap individual readiness for change. Peneliti menyarankan untuk penelitian yang akan datang dalam meneliti tentang individual readiness for change agar melihat dari sudut pandang struktural juga seperti yang disebutkan oleh Holt, et al (2010) yaitu sejauh mana pengetahuan, kompetensi dan kemampuan individu yang diharapkan untuk berubah sesuai dengan apa yang ingin dicapai dalam perubahan. Psychological capital yang dalam penelitian ini ditemukan tidak berpengaruh terhadap individual readiness for change, pada penelitian yang akan datang disarankan untuk menggunakan alat ukur psychological capital yang telah dioperasionalkan sesuai dengan konteks perubahan yang sedang dihadapi oleh organisasi yang diteliti. 


\section{REFERENSI}

Al-Hussami, M., Hammad, S., and Alsoleihat, F. (2018). The Influence of Leadership Behavior, Organizational Commitment, Organizational Support, Subjective Career Success on Organizational Readiness for Change in Healthcare Organizations. Leadership in Health Services, 31(4), 354-370. https://doi.org/10.1108/LHS-06-20170031

Armenakis, A. A., Harris, S. G., and Feild, H. S. (1999). Making Change Permanent: A Model for Institutionalizing Change Interventions. Research in Organizational Change and Development, 12, 97-128. http://dx.doi.org/10.1016/S0897-3016(99)12005-6

Avey, J. B. (2014). The Left Side of Psychological Capital: New Evidence on the Antecedents of PsyCap. Journal of Leadership and Organizational Studies, 21(2), 141-149. https://doi.org/10.1177/1548051813515516

Avey, J. B., Reichard, R. J., Luthans, F., \& Mhatre, K. H. (2011). Meta-Analysis of the Impact of Positive Psychological Capital on Employee Attitudes, Behaviors, and Performance. Human Resource Development Quarterly, 22(2), 127-152. https://doi.org/10.1002/hrdq

Avey, J. B., Wernsing, T. S., and Luthans, F. (2008). Can Positive Employees Help Positive Organizational Change?: Impact of Psychological Capital And Emotions on Relevant Attitudes and Behaviors. Journal of Applied Behavioral Science, 44(1), 48-70. https://doi.org/10.1177/0021886307311470

Babenroth, R., and Bartnik, R. (2019). Case 4: Japanese Cross Border M\&A and German Target Employee Alienation Issues. In A. Malik (Ed.), Strategic Human Resource Management and Employment Relations an International Perspective (pp. 175-180). Springer Nature Singapore. https://link.springer.com/chapter/10.1007/978-981-13-03999_18\#citeas

Bouckenooghe, D., and Devos, G. (2007). Psychological Change Climate as a Crucial Catalyst of Readiness for Change: A Dominance Analysis. https://public.vlerick.com/Publications/d5cf3931-6aa9-e011-8a89-005056a635ed.pdf

Bouckenooghe, D., Devos, G., and Broeck, H. Van den. (2009). Organizational Change Questionnaire-Climate of Change, Processes, and Readiness: Development of a New Instrument. Journal of Psychology: Interdisciplinary and Applied, 143(6), 559-599. http://ovidsp.ovid.com/ovidweb.cgi?T $=J S \& P A G E=$ reference $\& D=$ emed9\&NEWS=N\&A $\mathrm{N}=19957876$

Bruch, H., Gerber, P., and Maier, V. (2005). Strategic Change Decisions: Doing the Right Change Right. Journal of Change Management, 5(1), 97-107. https://doi.org/10.1080/14697010500067390

Burns, K. L. (2016). Perceived Organizational Support and Perceived Supervisor Support as Antecedents of Work Engagement [San José State University]. https://doi.org/https://doi.org/10.31979/etd.8hf7-dh9p

Eisenberger, R., Armeli, S., Rexwinkel, B., Lynch, P. D., \& Rhoades, L. (2001). Reciprocation of Perceived Organizational Support. Journal of Applied Psychology, 86(1), 42-51. https://doi.org/10.1037/0021-9010.86.1.42

Eisenberger, R., Huntington, R., Hutchison, S., and Sowa, D. (1986). Eisenberger 1986 JAppPsychol POS Original Article. Journal of Applied Psychology, 71(3), 500-507.

Emerson, R. M. (1976). Social Exchange Theory. Annual Review of Sociology, 2(1), 335-362. https://doi.org/10.4324/9781315204321-25

Ghozali, I., and Hengky, L. (2015). Konsep, Teknik dan Aplikasi Menggunakan Program Smart PLS 3.0. In Universitas Diponegoro. Semarang.

Gigliotti, R., Vardaman, J., Marshall, D. R., and Gonzalez, K. (2019). The Role of Perceived 
Organizational Support in Individual Change Readiness. Journal of Change Management, 19(2), 86-100. https://doi.org/10.1080/14697017.2018.1459784

Hair, J. F., Hult, G. T. M., Ringle, C. M., and Sarstedt, M. (2017). A Primer on Partial Least Squares Structural Equation Modeling (PLS-SEM). In Sage (Second Edi). Sage Publications.

Hanpachern, C., Morgan, G. A., and Griego, O. V. (1998). An Extension of The Theory of Margin: a Framework for Assessing Readiness for Change. Human Resource Development Quarterly, 9(4), 339-350. https://doi.org/10.1002/hrdq.3920090405

Hobfoll, S. E. (2002). Social and Psychological Resources and Adaptation. Review of General Psychology, 6(4), 307-324. https://doi.org/10.1037/1089-2680.6.4.307

Holt, D. T., Helfrich, C. D., Hall, C. G., and Weiner, B. J. (2010). Are You Ready? How Health Professionals Can Comprehensively Conceptualize Readiness for Change. Journal of General Internal Medicine, 25(SUPPL. 1), 50-55. https://doi.org/10.1007/s11606-009-1112-8

Hui, Q., Cao, X., Lou, L., and He, H. (2014). Empirical Research on the Influence of Organizational Support on Psychological Capital. American Journal of Industrial and Business Management, 04(04), 182-189. https://doi.org/10.4236/ajibm.2014.44025

Jabbarian, J., \& Chegini, M. G. (2017). The Effect of Perceived Organizational Support on Employee Resistance to Change: A Study on Guilan Municipal Staff. Journal of History Culture and Art Research, 5(4), 642. https://doi.org/10.7596/taksad.v5i4.627

Kirrane, M., Lennon, M., O'Connor, C., and Fu, N. (2017). Linking Perceived Management Support with Employees' Readiness for Change: The Mediating Role of Psychological Capital. Journal of Change Management, 17(1), 47-66. https://doi.org/10.1080/14697017.2016.1214615

Luthans, F., Norman, S. M., Avolio, B. J., and Avey, J. B. (2008). The Mediating Role of Psychological Capital in The Supportive Organizational Climate- Employee Performance Relationship. Journal of Organizational Behavior, 29, 219-238. https://doi.org/10.1002/job

Luthans, F., Youssef, C. M., and Avolio, B. J. (2007). Psychological Capital: Developing the Human Competitive Edge. In Psychological Capital: Developing the Human Competitive Edge. https://doi.org/10.1093/acprof:oso/9780195187526.001.0001

Madsen, S. R., Miller, D., and John, C. R. (2013). Readiness for Organizational Change: Do Organizational Commitment and Social Relationships in The Workplace Make a Difference? Human Resource Development Quarterly, 16(2), 16(2), 213-234.

Miller, K. I., and Monge, P. R. (1985). Social Information and Employee Anxiety about Organizational Change. Human Communication Research, 11(3), 365-386. https://doi.org/10.1111/j.1468-2958.1985.tb00052.x

Ming-Chu, Y., and Meng-Hsiu, L. (2015). Unlocking the Black Box: Exploring the Link Between Perceive Organizational Support and Resistance to Change. Asia Pacific Management Review, 20(3), 177-183. https://doi.org/10.1016/j.apmrv.2014.10.003

Munawaroh, L., and Meiyanto, S. (2017). Well-Being Orang Tua, Pengasuhan Otoritatif, dan Perilaku Bermasalah pada Remaja. Jurnal Psikologi, 44(3), 185. https://doi.org/10.22146/jpsi.25381

Neves, P., and Eisenberger, R. (2014). Perceived Organizational Support and Risk Taking. Journal of Managerial Psychology, 29(2), 187-205. https://doi.org/10.1108/JMP-072011-0021

Rhoades, L., and Eisenberger, R. (2002). Perceived Organizational Support: a Review of the Literature. Journal of Applied Psychology, 87(4), 698-714. https://doi.org/10.1037/00219010.87.4.698

Rochmi, A., and Hidayat, A. E. (2019). The Mediating Role of Affective Commitment in 
Perceived Organizational Support and Readiness for Change. 229(Iciap 2018), 785-795. https://doi.org/10.2991/iciap-18.2019.65

Self, D. R., Armenakis, A. A., and Schraeder, M. (2007). Organizational Change Content, Process, and Context: A Simultaneous Analysis of Employee Reactions. Journal of Change Management, 7(2), 211-229. https://doi.org/10.1080/14697010701461129

Shah, N., Irani, Z., and Sharif, A. M. (2017). Big data in an HR Context: Exploring Organizational Change Readiness, Employee Attitudes and Behaviors. Journal of Business Research, 70, 366-378. https://doi.org/10.1016/j.jbusres.2016.08.010

Sihag, P., and Sarikwal, L. (2015). Effect of Perceived Organizational Support on Psychological Capital - A Study of IT Industries in Indian Framework. EJBO: Electronic Journal of Business Ethics and Organizational Studies, 20(2).

Turgut, S., Michel, A., Rothenhöfer, L. M., and Sonntag, K. (2016). Dispositional Resistance to Change and Emotional Exhaustion: Moderating Effects at The Work-Unit Level. European Journal of Work and Organizational Psychology, 25(5), 735-750. https://doi.org/10.1080/1359432X.2016.1157583

$\mathrm{Wu}$, W. Y., and Nguyen, K. V. H. (2019). The Antecedents and Consequences of Psychological Capital: A Meta-Analytic Approach. Leadership and Organization Development Journal, 40(4), 435-456. https://doi.org/10.1108/LODJ-06-2018-0233 